outward physical circumstances, but also of principles of human nature, even morality and social habits, the progress even of medical science, the laws of inheritance and evolution, and the like. And, consequently, from the nature of the case, whatever partial uniformities of operation we may discover of the force, death, we cannot express the action in a general mathematical formula.

Not merely, therefore, do I believe that no law of mortality has been discovered which is capable of being exhibited in a mathematical shape, but I also think, from the nature of the subject, that it is futile to expect that such a result will ever be obtained.

In modifying series, accordingly, I am content, in our ignorance, whenever I desire to introduce an element into facts which they do not naturally present, to adopt some distributive process, like the excellent formula of $\mathrm{Mr}$ Woolhouse (which is not the mathematical expression of an assumed mortality law), or the old method of differences. To employ either of the formulas $I$ have referred to, on the ground of being a representation of a law of mortality, which the facts, when altered, are then imagined to reveal, would be, I consider, to assume a non-existent rule, and to make an unjustified interpretation.

It is, I admit, difficult at first to accept this view; for all our terms connected with the alteration of mortality tables involve the preconceived notion that a law exists, and is known: and the association of ideas is consequently strong. For example, the word "adjustment", from its derivation, carries with it the assumption that adjusting a series of numbers is really fitting them into accordance with a law; and the term "graduation", too,--meaning a progression by regular degrees,-involves again the affirmation of a standard or law.

Yours faithfully,

Commercial Union Assurance Co., T. E. YOUNG. Cornhill, London, E.C. Dec. 1879.

\title{
DEATH RATES AMONG INFANTS IN SCOTLAND.
}

To the Editor of the Journal of the Institute of Actuaries.

Desa Sir,-I have been much interested by Professor Pell's communication in the Journal of the Institute of Actuaries for January 1879, on "The Rates of Mortality in New South Wales", and more especially by the very elear account which be gives at pages 262-5 of the method which he prefers for deducing, by means of registered births and deaths, and without reference to the notoriously incorrect enumerations of persons of each age furnished by census, the probabilities of living for a year at each of the ages $0,1,2,3$, and 4 .

The births and deaths that take place in Scotland are as perfectly registered as those of any country ; and I have accordingly thought it worth while to prepare the accompanying tables, by means of which the numbers and probabilities furnished by recent experience in this country during a series of years may be compared with the similar details for New South Wales which Professor Pell has given. 
My tables $\mathrm{D}$ and $\mathrm{E}$ are strictly in the form of those at pages 263-4 of his paper; and, in the calculation of the values of $q_{x}$, are treated without adjustment, and exactly according to my undérstanding of his original formulas.

It is perhaps doubtful whether the annual number of deaths at unspecified ages is in New South Wales so considerable as to justify any addition to the deaths recorded for each of the first five years of life. And positive assurance is lacking that any such number of births escape registration in the colony as would render an addition to the annual official statement of births desirable. It may, however, be gathered from Professor Pell's paper that he deems no adjustment of his Tables D and E either necessary or practicable ; and, most certainly, to make any such adjustments on the Scottish Tables would involve an illusory show of accuracy, and be an abuse of arithmetic.

The record of births in the Scottish Table D is, I believe, as accurate as a good Registration Act can make it. In the Scottish Table $\mathrm{E}$ there will be found, both in its Male and in its Female portion, additional columns, showing how many deaths at unspecified ages occurred in all Scotland during each of sixteen years. Hence sticklers for accuracy have it in their power to repeat my calculation, after distributing among the first five years of life such rateable proportion of the deaths occurring at unspecified ages as they may think proper.

I have only to add that, although the values attributed to $q_{x}$ and to $p_{x}$ are, in $m y$ statement, carried to seven decimal places, I am perfectly aware that five places would have been amply sufficient, and that the only purpose really served by the higher decimal places is to attest the honesty of the arithmetical work.

When working with the aid of the Arithmometer it is sometimes easier to retain than to discard superfluous figures. I make no pretension to extreme accuracy in stating the values of $q_{x}$ and $p_{x}$.

\section{Yours very truly,}

28 Albany St., Edinburgh,

WILLIAM ROBERTSON, M.D. December 1879.

TABLE D.-Births registered in Scotland during 15 years, 1859-73.

\begin{tabular}{|c|c|c|c|c|c|}
\hline \multicolumn{2}{|c|}{ Years. } & \multirow{2}{*}{$\begin{array}{c}\text { Males. } \\
54,628\end{array}$} & \multirow{2}{*}{ Females. } & \multicolumn{2}{|c|}{ Years. } \\
\hline 1 & $\mathbf{1 8 5 9}$ & & & 1859 & 1 \\
\hline 2 & 1860 & 54,409 & 51,220 & 1860 & 2 \\
\hline 3 & 1861 & 54,606 & 52,403 & 1861 & 3 \\
\hline 4 & 1862 & 55,257 & 51,812 & 1862 & 4 \\
\hline 5 & 1863 & 56,226 & 53,115 & 1863 & 5 \\
\hline 6 & 1864 & 57,374 & 54,959 & 1864 & 6 \\
\hline 7 & 1865 & 58,220 & 54,850 & 1865 & 7 \\
\hline 8 & 1866 & 58,360 & 55,307 & 1866 & 8 \\
\hline 9 & 1867 & 58,517 & 55,527 & 1867 & 9 \\
\hline 10 & 1868 & 59,222 & 56,292 & 1868 & 10 \\
\hline 11 & 1869 & 58,321 & 55,033 & 1869 & 11 \\
\hline 12 & 1870 & 58,959 & 56,431 & 1870 & 12 \\
\hline 13 & 1871 & 60,029 & 56,099 & 1871 & 13 \\
\hline 14 & 1872 & 61,293 & 57,472 & 1872 & 14 \\
\hline 15 & 1873 & 61,467 & 58,233 & 1873 & 15 \\
\hline
\end{tabular}




\begin{tabular}{|c|c|c|}
\hline \multirow{8}{*}{ 䱜 } & \multirow{2}{*}{ 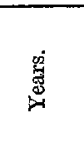 } & 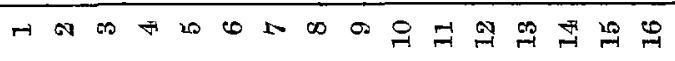 \\
\hline & & 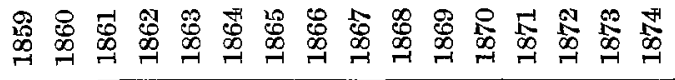 \\
\hline & 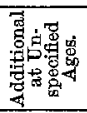 & 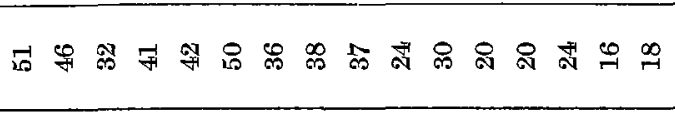 \\
\hline & if & 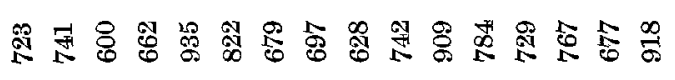 \\
\hline & ग्र & 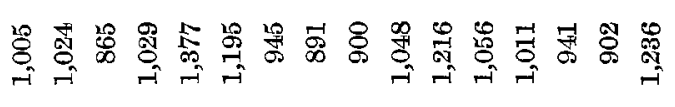 \\
\hline & $\stackrel{p}{a}$ & 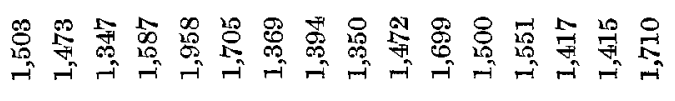 \\
\hline & $\underline{1}$ & 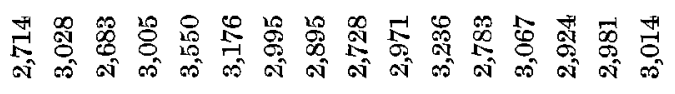 \\
\hline & $\mathfrak{o}$ & 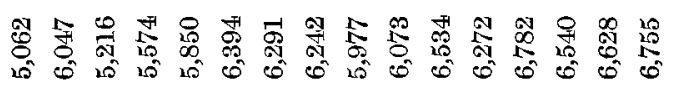 \\
\hline \multirow{9}{*}{ 昜 } & & \\
\hline &  & 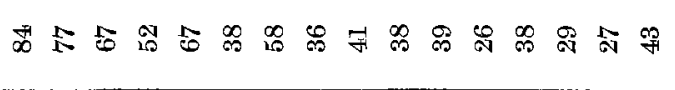 \\
\hline & $f$ &  \\
\hline & के & 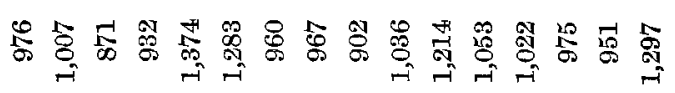 \\
\hline & and &  \\
\hline & $\stackrel{9}{-1}$ & 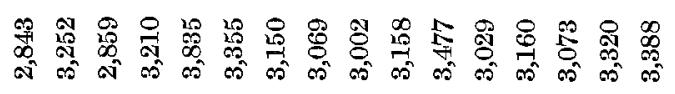 \\
\hline & ja & 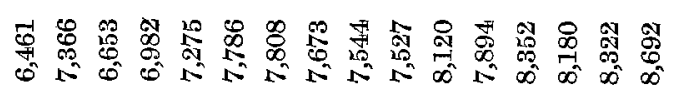 \\
\hline & $\stackrel{2}{3}$ & 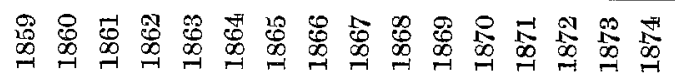 \\
\hline & & 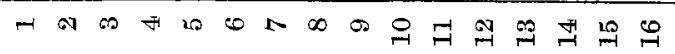 \\
\hline
\end{tabular}


1880.] Annual and Single Endowment Assurance Premiums. 143 Calculation, by Pell's Method, of q for the first Five Years of Life in Scotland.

\begin{tabular}{lrr} 
& \multicolumn{1}{c}{ Males. } & Females. \\
$\mathrm{B}_{0}$ & 866,888 & 820,668 \\
$\mathrm{~B}_{1}$ & 805,421 & 762,435 \\
$\mathrm{~B}_{2}$ & 744,128 & 704,963 \\
$\mathrm{~B}_{3}$ & 684,099 & 648,864 \\
$\mathrm{~B}_{4}$ & 625,140 & 592,433 \\
$\chi_{0}$ & 115,060 & 92,329 \\
$\chi_{1}$ & 45,017 & 42,015 \\
$\chi_{2}$ & 20,631 & 19,946 \\
$\chi_{3}$ & 12,852 & 12,615 \\
$\chi_{4}$ & 8,297 & 8,361 \\
$q_{0}$ & $\cdot 1327265$ & $\cdot 1125047$ \\
$q_{1}$ & $\cdot 0644462$ & $\cdot 0620919$ \\
$q_{2}$ & $\cdot 0341702$ & 0339909 \\
$q_{3}$ & $\cdot 0239732$ & $\cdot 0241783$ \\
$q_{4}$ & $\cdot 0173523$ & $\cdot 0179863$
\end{tabular}

NoTt.- The above calculations were made by the Arithmometer, without any attempt to shorten the arithmetical process by means of logarithms. 